\title{
Retraction Note to: Nucleation and growth rates of lactose as affected by ultrasound in aqueous solution
}

\author{
Mohammad Hassan Zamanipoor ${ }^{1}$. \\ Tuna Derya Dincer ${ }^{2}$ - Bogdan Zisu ${ }^{3}$. \\ Vijay Jayasena ${ }^{2}$
}

Received: 18 September 2012 / Revised: 6 December 2012 / Accepted: 19 December 2012 / Published online: 25 March 2016

(C) INRA and Springer-Verlag France 2015

\section{Retraction Note to: Dairy Sci. \& Technol. (2013) 93:995-604 DOI 10.1007/s13594-012-0106-1}

This article titled "Nucleation and growth rates of lactose as affected by ultrasound in aqueous solutions" and published in Volume 93, Issue 6, pages 595 - 604 has been retracted at the request of Curtin University resulting from an independent research misconduct inquiry conducted under the Australian Code for the Responsible Conduct of Research. Research misconduct was not found, however, the inquiry found that the paper was approved for final publication without the consent of all authors and recommended that the University request that the paper be retracted.

The online version of the original article can be found under http://dx.doi.org/10.1007/s13594-012-0106-1.

Mohammad Hassan Zamanipoor

zamanipoor@gmail.com

Vijay Jayasena

v.jayasena@curtin.edu.au

1 School of Biomedical Sciences, Curtin University, GPO Box U1987, Perth, WA 6845, Australia

2 Food Science and Technology Program, School of Public Health, Curtin Health Innovation Research Institute, Curtin University, GPO Box U1987, Perth, WA 6845, Australia

3 Dairy Innovation Australia Ltd, Werribee, VIC 3030, Australia 